\title{
NR2B and NR2D Subunits Coassemble in Cerebellar Golgi Cells to Form a Distinct NMDA Receptor Subtype Restricted to Extrasynaptic Sites
}

\author{
Stephen G. Brickley, ${ }^{1 \star}$ Charu Misra, ${ }^{1 \star}$ M. H. Selina Mok, ${ }^{1}$ Masayoshi Mishina, ${ }^{2}$ and Stuart G. Cull-Candy ${ }^{1}$ \\ ${ }^{1}$ Department of Pharmacology, University College London, London WC1E 6BT, United Kingdom, and ${ }^{2}$ Department of Molecular Neurobiology and \\ Pharmacology, University of Tokyo, Tokyo 113-0033, Japan
}

\begin{abstract}
NMDA receptors (NMDARs) are thought to be tetrameric assemblies composed of NR1 and at least one type of NR2 subunit. The identity of the NR2 subunit (NR2A, -B, -C, -D) is critical in determining many of the functional properties of the receptor, such as channel conductance and deactivation time. Further diversity may arise from coassembly of more than one type of NR2 subunit, if the resulting triheteromeric assembly (NR1 plus two types of NR2) displays distinct functional properties. We have used gene-ablated mice (NR2D - / ) to examine the effects of the NR2D subunit on NMDAR channels and NMDAR EPSCs in cerebellar Golgi cells. These cells are thought to express both NR2B and NR2D subunits, a combination that occurs widely in the developing nervous system. Our experiments provide direct evidence that the low conductance NMDAR channels in Golgi cells arise from diheteromeric NR1/NR2D assemblies. To investigate whether a functionally distinct triheteromeric assembly was also expressed, we analyzed the kinetic and pharmacological properties of single-channel currents in isolated extrasynaptic patches. We found that after the loss of the NR2D subunit, the properties of the $50 \mathrm{pS}$ NMDAR channels were altered. This result is consistent with the presence of a triheteromeric assembly (NR1/NR2B/NR2D) in cells from wild-type mice. However, we could find no difference in the properties of NMDAR-mediated EPSCs between wild-type and NR2D subunit ablated mice. Our experiments suggest that although both diheteromeric and triheteromeric NR2D-containing receptors are expressed in cerebellar Golgi cells, neither receptor type participates in parallel fiber to Golgi cell synaptic transmission. The presence of the NR2D subunit within an assembly may therefore result in its restriction to extrasynaptic sites.
\end{abstract}

Key words: NMDA receptor; NR2 subunits; cerebellum; synaptic and extrasynaptic receptors; receptor targeting; patch-clamp study

\section{Introduction}

NMDA receptors (NMDARs) play key roles in excitatory synaptic transmission, plasticity, and certain pathological changes in the CNS. The involvement of the NMDAR in these varied processes reflects its unique features, which depend critically on subunit composition. Molecular methods have identified various NMDAR subunits, including the ubiquitously expressed NR1 subunit, a family of distinct NR2 subunits (NR2A, -B, -C, and -D) and two NR3 subunits (Moriyoshi et al., 1991; Kutsuwada et al., 1992; Sugihara et al., 1992; Monyer et al., 1994; Das et al., 1998; Hollmann 1999). Most NMDARs are suggested to contain two copies of NR1 (Béhé et al., 1995) and two copies of NR2 (Premkumar and Auerbach, 1997; Laube et al., 1998).

Several functionally distinct NMDAR subtypes have been identified that are associated with each of these NR2 subunits (Farrant et al., 1994; Monyer et al., 1994; Momiyama et al., 1996; Vicini et al., 1998; Wyllie et al., 1998; Dingledine et al., 1999).

\footnotetext{
Received March 5, 2003; revised April 10, 2003; accepted April 14, 2003.

This work was supported by the Wellcome Trust. C.M. was in receipt of a Wellcome Fellowship, and M.H.S.M was funded by the Wellcome Trust 4-year PhD program in Neuroscience. S.G.C.-C. holds a Royal Society-Wolfson Research Merit Award. We thank Beverley Clark, Mark Farrant, June Liu, and Alasdair Gibb for helpful discussion.

*S.G.B. and C.M. contributed equally to this work.

Correspondence should be addressed to Dr. S. G. Cull-Candy, Department of Pharmacology, University College London, Gower Street, London WC1E 6BT, UK. E-mail: s.cull-candy@ucl.ac.uk.

S. G. Brickley's present address: Department of Biological Sciences, Imperial College London, London, SW7 2AZ UK.

C. Misra's present address: Department of Biochemistry, New York University, New York, NY 10016.

Copyright @ 2003 Society for Neuroscience $\quad$ 0270-6474/03/234958-09\$15.00/0
}

Further diversity is likely to arise from the presence of different NR2 subunits within an assembly. Indeed, there is compelling evidence that some native NMDARs contain more than one type of NR2 subunit (Sheng et al., 1994; Chazot and Stephenson, 1997; Dunah et al., 1998). Also, differences in the pharmacological and kinetic properties of macroscopic NMDAR currents have been used to infer the presence of triheteromeric assemblies in vivo (Tovar and Westbrook, 1999; Cathala et al., 2000). Because NR2B and NR2D subunits are known to predominate in the CNS of younger animals (Akazawa et al., 1994; Monyer et al., 1994), we have investigated whether this subunit combination forms triheteromeric receptors with distinct functional properties and, more importantly, to what extent these receptors participate in synaptic transmission.

Earlier work has demonstrated that cerebellar Golgi cells express a mixed population of high- and low-conductance NMDARs, interpreted as reflecting the presence of NR1/NR2B and NR1/NR2D subunit-containing NMDARs (Misra et al., 2000a). To investigate whether NR2B and NR2D may also coassemble to form a distinct triheteromeric assembly, we have compared NMDAR channel activity in cerebellar Golgi cells from wild-type and NR2D -/- (GluRe4-/-) mice (Ikeda et al., 1995; Misra et al., 2003).

This approach provided direct evidence that the NR2D subunit is involved in the generation of native low-conductance NMDAR channels, as proposed previously (Momiyama et al., 1996; Wyllie et al., 1996; Misra et al. 2000a; Momiyama 2000). 
Furthermore, a large proportion of the high-conductance openings in Golgi cells appeared to arise from NR1/NR2B/NR2Dcontaining receptors in wild-type mice. Although the singlechannel conductance of this novel extrasynaptic NMDAR population was indistinguishable from diheteromeric NR1/ NR2B receptors, it differed in kinetic and pharmacological properties. Because di- and triheteromeric NR2D receptors are confined to extrasynaptic regions in cerebellar cells (Momiyama et al., 1996; Misra et al., 2000), our results suggest that the presence of NR2D within an assembly may result in its restriction to extrasynaptic sites. Given the widespread distribution of NR2D subunits in cerebellar cells (Cull-Candy et al., 1998) and elsewhere (Dunah et al., 1998; Thompson et al., 2002), this raises the possibility that NR2D-containing receptors may not reach synaptic sites, even when identified extrasynaptically.

\section{Materials and Methods}

Slice preparation. C57BL/6 and NR2D -/ - mice (7-10 d old) (Ikeda et al., 1995) were used in these experiments. Before this study was performed, the genetic background of the NR2D $-/-$ strain had been purified by a series of 17 backcrosses into the C57BL/6 strain, such that the NR2D - / - strain was $99.99 \%$ genetically homogeneous with our wildtype controls (Takeuchi et al., 2001). Preparation of cerebellar slices was performed in accordance with the UK Animals (Scientific Procedures) Act, 1986. After decapitation, the brain was removed rapidly and cooled in saline $\left(2-4^{\circ} \mathrm{C}\right)$. Slices $(200-250 \mu \mathrm{m}$ thick $)$ were cut from the dissected cerebellar vermis in a sagittal orientation with a moving blade microtome (DTK-1000; Dosaka EM Co., Kyoto, Japan). These were then incubated in slicing solution at $34^{\circ} \mathrm{C}$ for $1 \mathrm{hr}$ and subsequently maintained at room temperature for up to $8 \mathrm{hr}$. The saline solution used for slicing and incubation contained (in $\mathrm{mm}$ ): $125 \mathrm{NaCl}, 2.5 \mathrm{KCl} 2.5,1 \mathrm{CaCl}_{2}, 4 \mathrm{MgCl}_{2}$, $26 \mathrm{NaHCO}_{3}, 1.25 \mathrm{NaH}_{2} \mathrm{PO}_{4}, 25$ glucose, $\mathrm{pH}$ 7.4, when bubbled with $95 \%$ $\mathrm{O}_{2}$ and $5 \% \mathrm{CO}_{2}$. For patch-clamp experiments, slices were transferred to a recording chamber and viewed on an Axioskop-FS microscope (Zeiss, Welwyn Garden City, UK).

Solutions. The standard external solution used for single-channel recording experiments was the same as the slicing solution, except that $\mathrm{Mg}^{2+}$ was omitted. In experiments in which synaptic currents were recorded, external $\mathrm{Ca}^{2+}$ was raised from 1 to $2 \mathrm{~mm}$. The internal solution, used for recording from outside-out patches, contained (in $\mathrm{mM}$ ): 140 $\mathrm{CsCl}, 4 \mathrm{NaCl}, 0.5 \mathrm{CaCl}_{2}, 10 \mathrm{HEPES}, 5 \mathrm{EGTA}, 2 \mathrm{Mg}$-ATP (adjusted to $\mathrm{pH}$ 7.3 with $\mathrm{CsOH}$ ). Whole-cell recordings were made with an internal solution containing (in mM): $95 \mathrm{CsF}, 25 \mathrm{CsCl}, 10$ HEPES, 10 EGTA, $2 \mathrm{NaCl}$, 2 Mg-ATP, 10 QX-314 10, 5 tetraethylammonium chloride, 5 4-aminopyridine.

In experiments on outside-out patches, the following drugs were added to the $\mathrm{Mg}^{2+}$-free external solution: $10 \mu \mathrm{M}$ bicuculline methobromide (Research Biochemicals Inc., Natick, MA), 0.5-1 $\mu \mathrm{M}$ strychnine hydrochloride (Sigma, Poole, UK), $5 \mu \mathrm{M}$ 6-cyano-7-dinitroquinoxalinedione (Tocris Cookson, Bristol, UK). In some experiments ifenprodil (Sigma) or $N, N, N^{\prime}, N^{\prime}$-tetrakis-(2-pyridylmethyl)-ethylenediamine (TPEN; Sigma) was added to the perfusate. For activation of NMDARs, $10 \mu \mathrm{M}$ NMDA (Tocris) was applied with $10 \mu \mathrm{M}$ glycine $(\mathrm{BDH})$ in the presence of $300 \mathrm{~nm}$ tetrodotoxin (TTX; Sigma). Experiments investigating spontaneous and evoked EPSCs were performed in the presence of $10 \mu \mathrm{M}$ bicuculline and $0.5 \mu \mathrm{M}$ strychnine to block GABAergic and glycinergic spontaneous IPSCs, respectively (Dieudonné, 1995). TTX (1 $\mu \mathrm{M})$ was added to the external solution to allow us to record miniature EPSCs (mEPSCs).

Recording procedures. Recordings were made with an Axopatch-200A amplifier (Axon Instruments, Foster City, CA). Golgi cells were identified visually under Nomarski differential interference contrast optics (using $40 \times$ water-immersion objective; total magnification $320-1000 \times$ ). Golgi cells were readily identified within the internal granule cell layer of sagittal cerebellar slices from their morphological and electrical characteristics (Dieudonné, 1998; Misra et al., 2000a). Patch pipettes were made from thick-walled borosilicate glass capillary tubing (GC-150F; Clark
Electromedical) on a two-stage puller. Pipettes were then coated with Sylgard (Dow Corning 184) resin and fire polished. During whole-cell recording, we used $60-70 \%$ series resistance compensation (typically 7 $\mu$ sec lag-time). Parallel fiber inputs (granule cell axons) were stimulated with $30-45 \mathrm{~V}$ pulses of $40-300 \mu \mathrm{sec}$ duration at $0.2 \mathrm{~Hz}$ (Digitimer D4030 and Neurolog DS2 isolator; Digitimer Ltd., Welwyn Garden City, UK), delivered via a glass pipette that contained external solution or $1 \mathrm{M}$ $\mathrm{NaCl}$. The threshold for parallel fiber stimulation was deemed to have been reached when $50 \%$ of stimuli produced a detectable EPSC. The stimulus strength was then set at $15 \mathrm{~V}$ above this threshold.

Data analysis. Single-channel current records were collected on digital audiotape (DC - $20 \mathrm{kHz}$; DTR-1204; BioLogic, Claix, France), with the amplifier filter (four-pole Bessel type) set at $10 \mathrm{kHz}$. For analysis of single-channel currents, the records were replayed from tape, filtered at 2 $\mathrm{kHz}$, and digitized at $10 \mathrm{kHz}$ (pCLAMP 6.1, Axotape; Axon Instruments). The events were examined at potentials between -80 and +20 $\mathrm{mV}$, and histograms were constructed (pCLAMP 6.1, Fetchan). In such experiments, the mean single-channel current was estimated from Gaussian fits to the amplitude distributions. The amplitudes were then plotted against voltage, and the data were fitted by linear regression to give a slope-conductance and reversal potential.

The time course fitting method was used to analyze the transitions between the various conductance levels in greater detail (Colquhoun and Sigworth, 1995) (http://www.ucl.ac.uk/Pharmacology/dc.html). For this analysis, the currents were replayed from tape, filtered at $2 \mathrm{kHz}$, and digitized at $10 \mathrm{kHz}$ via a CED $1401+$ interface (Cambridge Electronic Design, Cambridge, UK). Individual openings were then fitted with the step response function of the recording system. Any events briefer than two filter rise times (i.e., $98.8 \%$ of their full amplitude) were excluded from the analysis of fitted amplitudes. In contrast with all-point amplitude distributions, the resulting fitted amplitude distributions convey no information regarding the time spent at any given amplitude. Kinetic information was obtained from analysis of open period and shut time distributions and the subsequent calculation of open probability.

The unbinned amplitude data were fitted to the sum of two or three Gaussian components, using the maximum likelihood method, to give mean amplitude levels of the single-channel currents. The Gaussian fits of the amplitude histogram were used to estimate the critical amplitude that would serve as a "cutoff" between the 40 and the $50 \mathrm{pS}$ conductance states (Howe et al., 1991). The critical amplitude was chosen as the value that resulted in the least number of misclassified events within each group. This critical amplitude approach was chosen to analyze the openperiod kinetics of high-conductance openings $\left(\right.$ open period $_{\mathrm{HIGH}}$ ) and therefore calculate the open probability of this high-conductance NMDAR population $\left(\mathrm{P}_{\mathrm{OPEN}(\mathrm{HIGH})}\right)$ with little contamination from lowconductance NR1/NR2D-like openings. Therefore, for wild-type NMDAR openings, only a fraction of the $8 \pm 1 \%$ misclassified events will arise from low-conductance NR1/NR2D-like openings, because the majority of misclassified events will correspond to the subconductance state $(\sim 40 \mathrm{pS})$ of the high-conductance openings (see Results).

EPSCs were filtered at $2 \mathrm{kHz}$ and digitized at $10 \mathrm{kHz}$. EPSCs were identified by eye from the digitized records and analyzed using " $N$ " v1.0 software (written by Stephen Traynelis, Emory University, Atlanta, GA). Average waveforms were constructed by aligning EPSCs on their initial rising phase. Decay phases were fitted using either "N" or Origin 4.10 (Microcal, Northampton MA). For both spontaneous and evoked synaptic currents, the decay phase was well described by the sum of two exponential functions.

Ifenprodil inhibition curves were fitted with a modified form of the Hill equation with the fit weighted to the SD at each concentration using Igor Pro (Wavemetrics, Lake Oswego, OR): $I=I_{\max } /\left(1+\left([A] / \mathrm{IC}_{50}\right)^{n}+\right.$ $\left(100-I_{\max }\right)$, where $I$ is the response magnitude, $I_{\max }$ is the maximal inhibition of the response, $[A]$ is the concentration of ifenprodil, $\mathrm{IC}_{50}$ is the concentration of ifenprodil required to reduce the response to $50 \%$ of the maximum block, and $n$ is the Hill slope.

A simple modification of this single-component model (Kew et al., 1998) was applied to the data when attempting to describe the presence of both high $\left(\mathrm{IC}_{50(\mathrm{H})}\right)$ and low affinity $\left(\mathrm{IC}_{50(\mathrm{~L})}\right)$ ifenprodil inhibition: $I=$ 
$I_{\max (\mathrm{H})} /\left(1+\left([A] / \mathrm{IC}_{50(\mathrm{H})}\right)^{n(\mathrm{H})}\right)+I_{\max (\mathrm{L})} /\left(1+\left([A] / \mathrm{IC}_{50(\mathrm{~L})}\right)^{n(\mathrm{~L})}+\right.$ $\left(100-I_{\max (\mathrm{H})}-\mathrm{I}_{\max (\mathrm{L})}\right.$.

Statistical analysis. All values are expressed as the mean \pm SEM. All data sets used for statistical analysis were normally distributed (ShapiroWilks' $W$ test). Therefore, differences between groups could be tested using either a paired or unpaired two-tailed Student's $t$ test and were considered significant at the $p<0.05$ level.

\section{Results}

Low-conductance openings arise from

NR2D-containing NMDARs

The steady-state application of $10 \mu \mathrm{M}$ NMDA (together with 10 $\mu \mathrm{M}$ glycine) activated discrete single-channel currents in outsideout patches excised from the soma of Golgi cells. In wild-type mice, these openings were predominantly $\sim 50 \mathrm{pS}(53.47 \pm 0.8$ $\mathrm{pS} ; n=15$ ) with a brief $\sim 40 \mathrm{pS}$ subconductance. These events resembled the conventional "high-conductance" (50-40 pS) NMDAR channel openings that have been widely described (for review, see Cull-Candy et al., 2001). In addition, a distinct "lowconductance" type of NMDAR channel was evident in these patches. As is apparent in Figure $1 A$, the low-conductance openings $(\sim 40$ and $\sim 20 \mathrm{pS}$ ) were characterized by frequent direct transitions between levels. We have previously observed a similar pattern of NMDAR channel openings in rat Golgi cells (Misra et al., 2000a) and other central neurons (Momiyama et al., 1996). As in the rat, the occurrence of these low-conductance openings was much less frequent than the high-conductance openings, reflecting the low open probability of this NR1/NR2D channel population (Wyllie et al., 1998; Misra et al., 2000b).

Time-course fitting of single-channel currents recorded in outside-out patches from wild-type animals (see Materials and Methods) revealed three discrete peaks in the fitted amplitude histograms (Fig. 1A). When data from these patches were pooled, $48.9 \pm 5.8 \%(13,382$ fitted amplitudes $)$ of openings were to the high-conductance $(50 \mathrm{pS})$ state. The subconductance, observed within these high-conductance channels, was characterized by an occasional brief sojourn to a $40 \mathrm{pS}$ state. However, lowconductance events, not linked to the high-conductance $50 \mathrm{pS}$ channels, were also present in all patches examined $(n=15)$. These had a mean conductance of $43.4 \pm 1.2 \mathrm{pS}$ with a subconductance of $23.1 \pm 0.7 \mathrm{pS}$, similar to low-conductance NMDAR channels that have been described in outside-out patches from rat Golgi cells (Misra et al., 2000a). Moreover, when we analyzed 1113 direct transitions that occurred between the main and subconductance state of the low-conductance channels, $65.6 \pm 2.5 \%$ arose as transitions from the 40 to the $20 \mathrm{pS}$ state, corresponding well to the transition rate of $64 \%$ reported previously for lowconductance NMDAR openings in rat Golgi and Purkinje cells (Momiyama et al., 1996; Misra et al., 2000a).

In contrast, the application of $10 \mu \mathrm{M}$ NMDA to Golgi cell patches from NR2D $-/-$ mice appeared to activate only highconductance events of $\sim 50$ and $40 \mathrm{pS}$ (Fig. $1 \mathrm{~B}$ ). Therefore, fitted amplitude histograms (Fig. $1 B$ ) constructed from these openings exhibited a main peak and a shoulder corresponding to the infrequent $\sim 40 \mathrm{pS}$ subconductance state that contributed $<10 \%$ to the total number of events in this example. As is apparent from Figure $2 A$, in all 15 patches from wild-type mice, the three main conductance states were clearly present (obtained from Gaussian fits to the fitted amplitude histograms); these corresponded to high- and low-conductance NMDAR channels. In contrast, isolated low-conductance events were absent from all Golgi cell patches obtained from NR2D - /- mice.

We next compared the slope conductance of the highconductance channels from wild-type and NR2D $-/-$ mice over
A
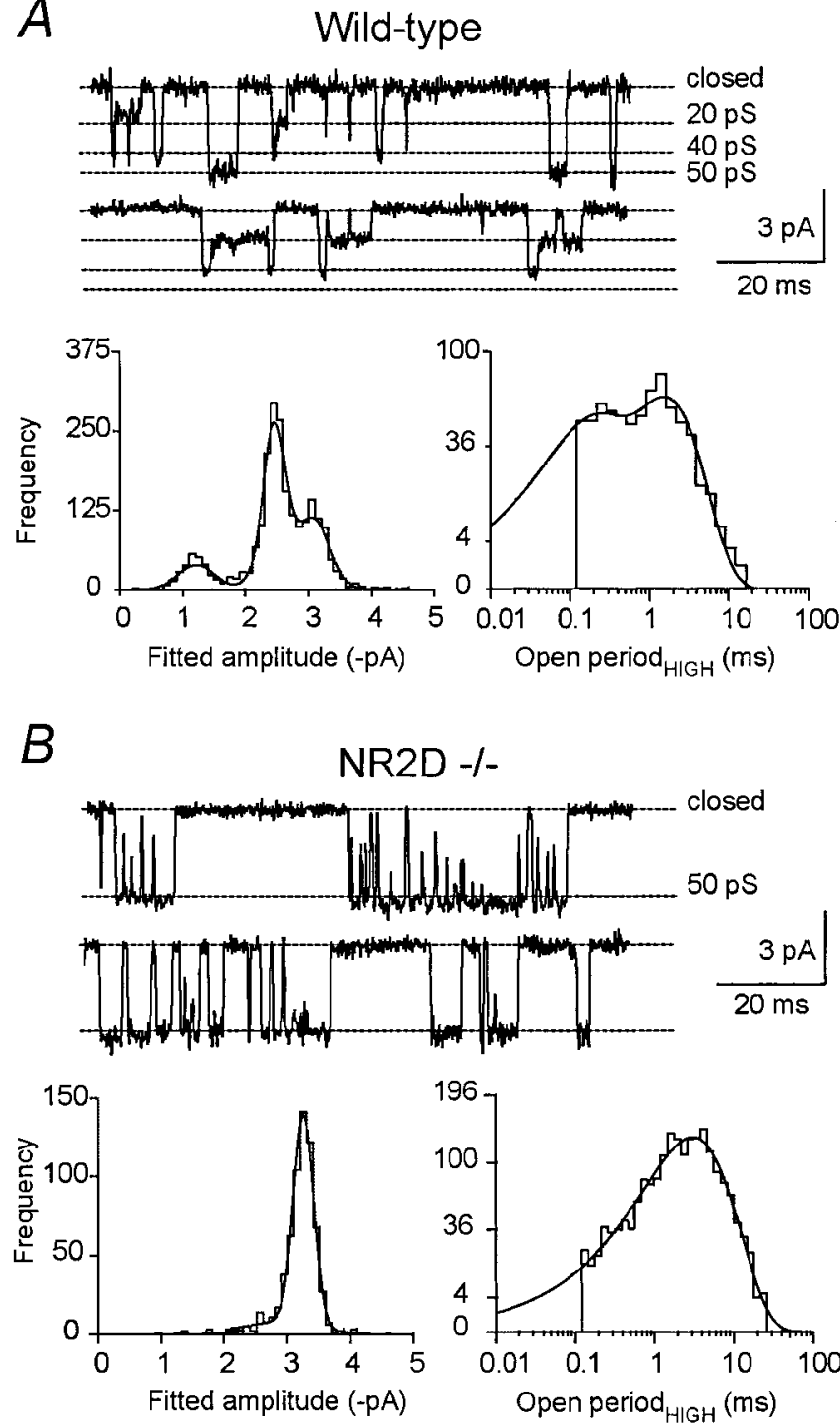

Figure 1. Single-channel properties of Golgi cell NMDARs in wild-type and NR2D - /mice. $A$, Single-channel currents from an outside-out patch $(-60 \mathrm{mV})$ excised from a Golgi cell soma in a wild-type mouse (P8). Channel activity was evoked in response to $10 \mu \mathrm{m}$ NMDA and $10 \mu \mathrm{m}$ glycine. A mixed population of 50, 40, and $20 \mathrm{pS}$ openings was observed (mean amplitudes indicated by dashed lines) in wild-type mice. Stretches of record have been selected to illustrate examples of low-conductance openings (along with high-conductance events). Note, however, that the frequency of low-conductance openings is generally low in Golgi cells. Bot-

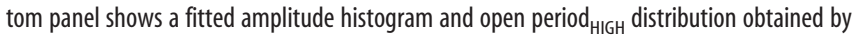
time course fitting of single-channel openings. Current amplitudes were fitted with the sum of three Gaussian distributions; open periods were fitted with the sum of two exponentials (note the log scale). In both cases a maximum likelihood fitting procedure was applied to ensure best fit. $B$, Single-channel currents from an outside-out patch $(-60 \mathrm{mV})$ from an NR2D - /mouse (P8). Note the absence of low-conductance openings, in both the single-channel recordings and the amplitude distribution (bottom left-hand panel). Amplitudes were fitted with the sum of two Gaussian distributions ( $\sim 50$ and $40 \mathrm{pS}$, corresponding to high-conductance type openings), and open periods were fitted with the sum of two exponentials.

a range of potentials $(n=16$ patches from wild type; $n=7$ patches from NR2D $-/-)$. The slope conductance estimates were similar in both strains: $50.1 \mathrm{pS}$ for wild-type animals and 49.7 pS for NR2D -/ - (Fig. 2 B). Furthermore, in the knock-out animals, measurement of the main and the subconductance levels (constructed from Gaussian fits to amplitudes) gave a main single-channel conductance of $53.9 \pm 1.7 \mathrm{pS}(77.5 \pm 1.4 \%$ of events; $n=14$ patches) and a subconductance of $46.3 \pm 1.3 \mathrm{pS}$. 

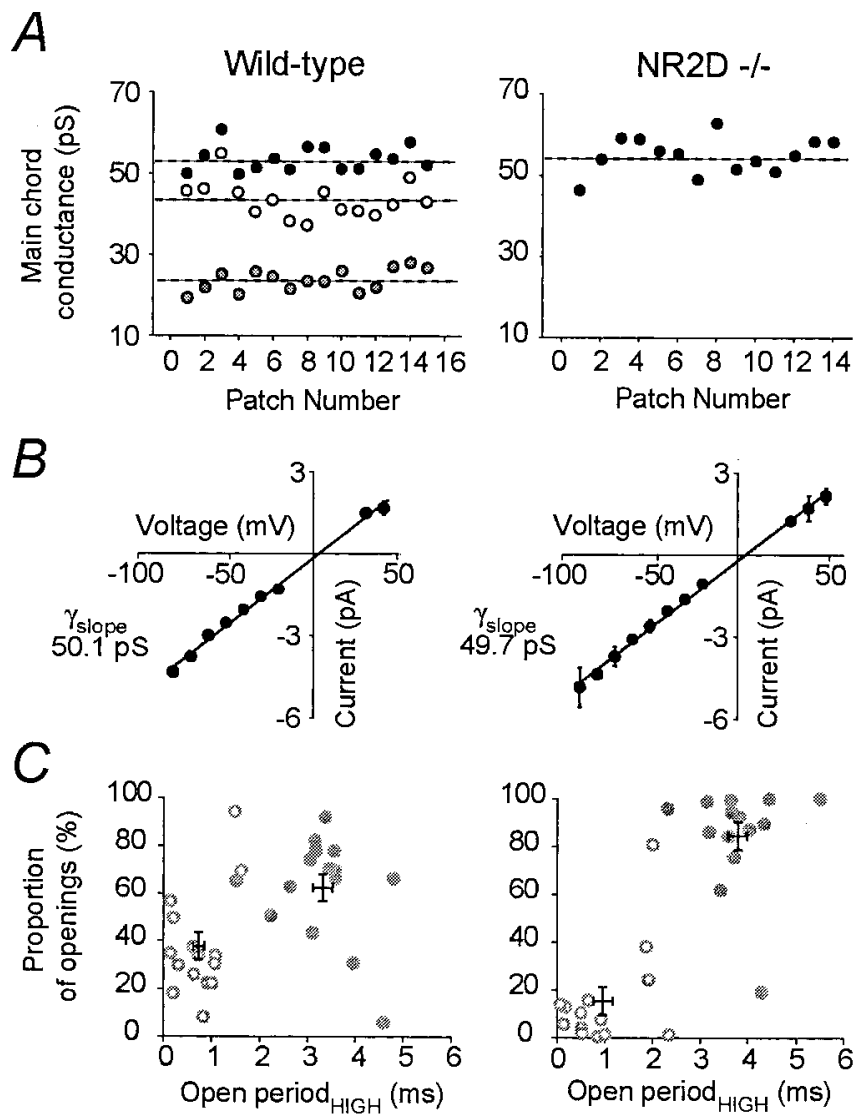

Figure 2. Comparison of main conductance states and open period ${ }_{H I G H}$ distributions in wildtype and NR2D - / - animals. A, Plots of the main chord conductance measurements obtained from outside-out patches in wild-type and NR2D - / - animals. In the wild-type animals, three main conductance states were present (dashed lines). Only high-conductance openings were observed in patches from NR2D - / - mice (indicated by a single dashed line; subconductances of the $50 \mathrm{pS}$ channels have not been included in wild-type or NR2D $-/-$ data). B, Slope conductance measurements of $\sim 50 \mathrm{pS}$ channels from wild-type and NR2D $-/-$ mice. Averaged data from patches from 16 wild-type and 7 NR2D - / - cells have been pooled, and the resulting $I-V$ relationship has been obtained by least squares fitting to give the slope conductance. C, Comparison of all fits to the open period ${ }_{\mathrm{HIGH}}$ data from wild-type and NR2D - /mice. Distributions were best fit with a fast (open symbols) and a slow (filled symbols) time constant.

This was not significantly different from our estimates for highconductance channels in wild-type animals. This suggested that the NR2D subunit did not have a detectable effect on the amplitude of the main or subconductance state of the highconductance channels in these cells, nor did it appear to introduce additional conductance states to this channel.

\section{Kinetic properties of high-conductance NMDAR channels are} modified in NR2D $-/-$ animals

We next considered whether the kinetic properties of the highconductance openings (open periods) were affected by the presence of the NR2D subunit. For the purpose of our analysis we considered the open period of the channel to be the total time that it remained open at its various conductance levels between full closures. A full closure was deemed to have occurred once the channel had closed for a period exceeding twice the filter rise time. In the present study we analyzed the open periods of the

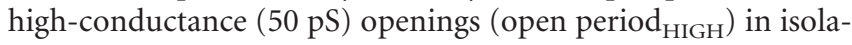
tion by defining critical amplitudes that separate the highconductance $(50 \mathrm{pS})$ openings from the other $(20 / 40 \mathrm{pS})$ states.
A
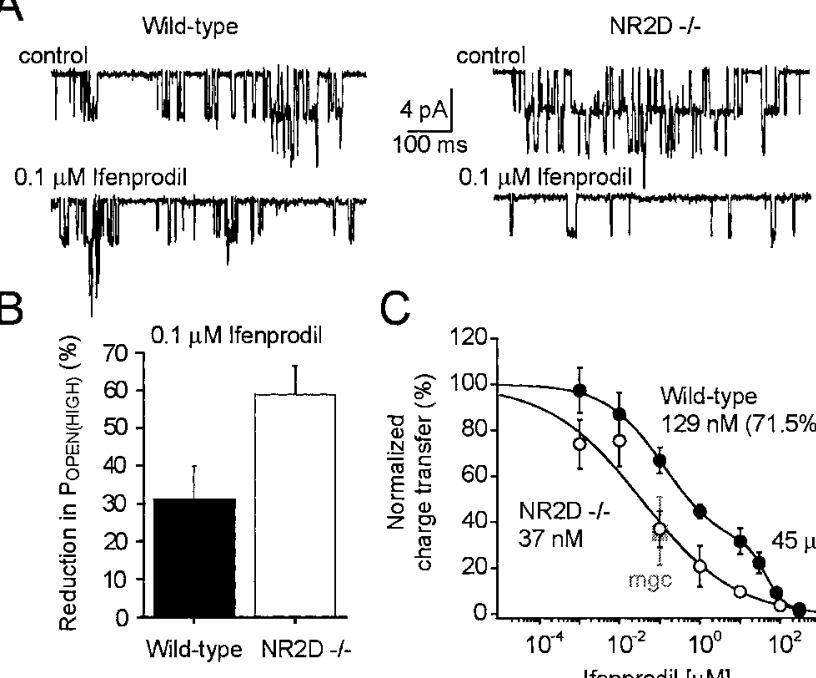

C

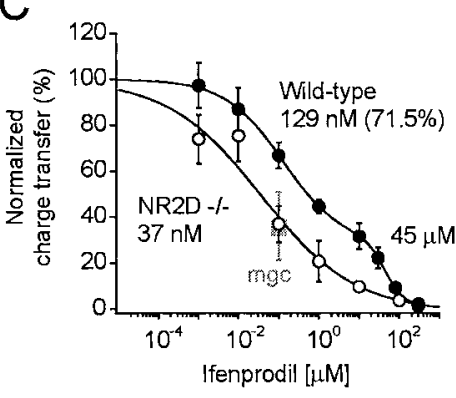

Figure 3. Ifenprodil sensitivity of high-conductance NMDAR openings in wild-type and NR2D - / - mice. A, Continuous single-channel current records showing the effect of $0.1 \mu \mathrm{m}$ ifenprodil (bottom traces) on high-conductance NMDAR openings. In both wild-type and NR2D $-/-$ mice, $P_{\text {OPEN }}$ was clearly reduced. Note that in the records from NR2D $-/-$ NMDARs, channel openings appear longer in duration in control than in the ifenprodil. $B$, Comparison of the change in $\mathrm{P}_{\mathrm{OPEN}(\mathrm{HIGH})}$ produced by $0.1 \mu \mathrm{M}$ ifenprodil in wild-type and NR2D - / - NMDARs. The reduction was significantly greater in NR2D $-/-$. C, Concentration-inhibition relationship for the action of ifenprodil on single-channel charge transfer. Data represent 16 patches from wild-type mice (filled symbols) and 14 patches from NR2D - / - mice (open symbols). The relationship for wild-type mice was fitted with a modified Hill equation giving high- and low-affinity components with $\mathrm{IC}_{50}$ of $129 \mathrm{~nm}\left(I_{\max (\mathrm{H})}=71.5 \%\right)$ and $45 \mu \mathrm{m}$, respectively. The relationship for NR2D - / - mice was fit with a single-component Hill equation with $\mathrm{IC}_{50}$ of 37 $\mathrm{nm}$. For comparison a data point showing the degree of ifenprodil block (100 nm) for NMDARs recorded in migrating cerebellar granule cells (Misra et al., 2000a) has been added to this plot (gray symbol).

For example, the multiple peaks present in the wild-type data shown in Figure 1 were described by the sum of three Gaussian distributions. A critical amplitude was defined from the fit of these Gaussian distributions, such that $>90 \%$ of openings (wildtype: $92 \pm 1 \%, n=14$; NR2D $-/-: 91 \pm 2 \%, n=14)$ were of the high-conductance (50 pS) type (Howe et al., 1991).

It is worth noting that only a small proportion of events in this $40 \mathrm{pS}$ group will come from NR1/NR2D-like openings (i.e., the 20/40 pS group) because this channel population has a low open probability (Wyllie et al., 1998; Misra et al., 2000b). For example, in seven wild-type patches in which a sufficient number of lowand high-conductance openings were present within the same patch, time course fitting of NMDAR channel openings demonstrated that the average proportion of low-conductance $(20 / 40$ pS) events was $8.0 \pm 1.5 \%$ (range 5.2-15.9\%). Only a fraction of these events will then contribute to the "misclassified openings" because most of the $40 \mathrm{pS}$ group arises from the subconductance state of the $50 \mathrm{pS}$ openings.

From a cursory examination of the single-channel currents in patches from wild-type and NR2D $-/-$ mice (Figs. 1, 3A), the kinetic properties of high-conductance openings were clearly changed in the absence of the NR2D subunit. The highconductance NMDAR channel openings observed in wild-type patches were noticeably briefer than those observed in patches from the NR2D $-/-$ strain. Indeed, open period ${ }_{\mathrm{HIGH}}$ analysis demonstrated a significant difference in the kinetics of highconductance events in the two strains. This change in kinetics, after loss of the NR2D subunit, is evident in the open period ${ }_{\mathrm{HIGH}}$ 
distributions shown in Figure 1. For both wild-type and NR2D $-/-$ mice the distribution of open period $\mathrm{HIGH}_{\mathrm{H}}$ was best described by a double exponential fit. When data from a wild-type animal were plotted on a logarithmic scale, this distribution had two clear peaks. In contrast, although the distribution of open periods for high-conductance openings from NR2D - / - animals was also best described by a fast and slow component (Fig. $1 \mathrm{~B}$ ), the magnitude of the fast component was much reduced. This was true for all NR2D $-/-$ single-channel data. Consequently, in wild-type mice the fast component $\left(\tau_{\text {fast }}=732.6 \pm 122.6 \mu \mathrm{sec}\right.$; $n=15)$ contributed $37.7 \pm 5.6 \%$ to the open periods, whereas in NR2D $-/-$ mice it contributed only $15.4 \pm 5.8 \%\left(\tau_{\text {fast }}=\right.$ $971.7 \pm 203.6 \mu \mathrm{sec} ; n=14)$. We found no significant change in the time constant of either the fast or slow components $\left(\tau_{\text {slow }}=\right.$ $3.3 \pm 0.2 \mathrm{msec}$ in wild-type vs $\tau_{\text {slow }}=3.8 \pm 5.8 \mathrm{msec}$ in NR2D $-/-$ mice). Therefore, at this concentration of NMDA $(10 \mu \mathrm{M})$, the weighted mean open period for high-conductance events was $\tau=2.4 \pm 0.2 \mathrm{msec}(n=15)$ in wild-type mice, compared with $3.4 \pm 0.2 \mathrm{msec}(n=14)$ in NR2D $-/-$ mice. As is apparent in Figure $2 C$, which compares open period ${ }_{\mathrm{HIGH}}$ distributions in all patches from wild-type versus NR2D - / - mice, this represented a significant change in the weighted mean open period.

As a result of the difference in open periods, the probability of a high-conductance channel being open $\left(\mathrm{P}_{\mathrm{OPEN}(\mathrm{HIGH})}\right)$ was significantly greater in NR2D $-/-(0.04 \pm 0.004)$ than in wild-type $(0.02 \pm 0.004)$ mice. This observation is consistent with the idea that the NR2D subunit coassembles with NR2B to form a native triheteromeric (NR1/NR2B/NR2D) receptor with distinct singlechannel kinetics, but with a conductance that is indistinguishable from the diheteromeric NR1/NR2B receptor. The frequency of the high-conductance openings was also not significantly different between wild-type $(8.5 \pm 1.6 \mathrm{~Hz})$ and NR2D $-/-(11.2 \pm 1.8$ $\mathrm{Hz}$ ) animals. Furthermore, the shut-time distribution of highconductance events was similar between strains (data not shown). In both cases the shut-time distribution was well fitted with the sum of three exponential components, with weighted mean shut-times of $\tau=133.2 \pm 72.9 \mathrm{msec}(n=14)$ for wild-type and $\tau=77.0 \pm 13.1 \mathrm{msec}(n=14)$ for NR2D $-/-$ animals. These values were not significantly different.

\section{Ifenprodil sensitivity of high-conductance channels is modified by NR2D}

Coassembly of NR2B and NR2D subunits in Golgi cells might also be expected to influence the pharmacology of the highconductance (NR2B-containing) receptor (Vicini et al., 1998). We therefore examined the effect of the NR2B-selective antagonist ifenprodil (Williams, 1993) on high-conductance openings activated by $10 \mu \mathrm{M}$ NMDA. In patches from both wild-type and NR2D $-/-$ mice, $0.1 \mu \mathrm{M}$ ifenprodil caused a marked reduction in $\mathrm{P}_{\text {OPen(High) }}$. However, as shown in Figure $3, A$ and $B$, the degree of block was significantly greater in the absence of the NR2D subunit. Thus, comparison of the change in $\mathrm{P}_{\mathrm{OPEN}(\mathrm{HIGH})}$, after bath application of $0.1 \mu \mathrm{M}$ ifenprodil (Fig. $3 B$ ), revealed a reduction of only $31.2 \pm 8.7 \%(n=7)$ in wild-type versus $58.9 \pm$ $7.5 \%(n=8)$ in NR2D $-/-$ mice.

Figure $3 C$ illustrates the concentration-response relationship for the blocking action of ifenprodil, constructed from charge transfer analysis of all NMDAR openings in patches from wildtype and NR2D -/ - mice. The low open probability and low single-channel conductance of the NR1/NR2D-containing NMDARs would imply that they contribute little to the charge transfer data. To confirm this, we performed charge transfer analysis on the same patches that were used for time course fit- ting. The reduction in $\mathrm{P}_{\mathrm{OPEN}(\mathrm{HIGH})}$ was similar to the reduction in the total charge transfer. Thus, when $100 \mathrm{~nm}$ ifenprodil was applied to patches from wild-type mice, $\mathrm{P}_{\mathrm{OPEN}}$ analysis gave a reduction of $31 \pm 8 \%$, whereas total charge transfer analysis gave a reduction of $30 \pm 7 \%(n=7)$. This reduction in charge transfer was similar to that reported previously for rat Golgi cells (38\%) (Misra et al. 2000a). In the NR2D - /- mice, $\mathrm{P}_{\text {OPEN }}$ analysis gave a reduction of $60 \pm 9 \%$, whereas total charge transfer analysis gave a reduction of $63 \pm 5 \%(n=7)$. This result is consistent with the idea that the charge transfer analysis reflects the activity of high-conductance openings.

Concentration-response relationships for ifenprodil inhibition of NMDARs in patches from wild-type mice (Fig. 3) were best fitted with a modified form of the Hill equation with two $\mathrm{IC}_{50}$ components (see Materials and Methods). The identification of an additional component with apparent low affinity extends our previous observations on rat Golgi cell NMDARs, which were fitted with a single component Hill equation (Misra et al. 2000a). In the present study, the $\mathrm{IC}_{50}$ value for the apparent high-affinity component was $129 \mathrm{nM}$ with a Hill slope of 0.6 and $I_{\max (\mathrm{H})}$ of $71.5 \%$, whereas the apparent low-affinity component had an $\mathrm{IC}_{50}$ of $45 \mu \mathrm{M}$ with a Hill slope of 1.8 and $I_{\max (\mathrm{L})}$ of $28.5 \%$. Although the high-affinity component was present in both strains of mice, the lower-affinity component was absent in patches from NR2D $-/-$ animals. Therefore, these data were best fitted with a single Hill equation $\left(\mathrm{IC}_{50}=37 \mathrm{nM}\right.$; Hill slope $\left.=0.4\right)$. This degree of ifenprodil block is similar to that observed for a pure population of NR1/NR2B receptors found in migrating granule cells from the rat (Fig. 3C) (Misra et al., 2000a). Once again, the reduced blocking action of ifenprodil in patches from wild-type mice is consistent with the presence of a pharmacologically distinct population of channels containing coassembled NR2B and NR2D subunits. Although the basis of this reduced ifenprodil sensitivity remains to be elucidated, it may result from alterations in the $\mathrm{N}$-terminal LIV-binding protein-like domain of the coassembled receptor (Perin-Dureau et al., 2002).

To address the possibility that NR2A subunits might contribute to the extrasynaptic NMDAR population in these cells, we examined the actions of the $\mathrm{Zn}^{2+}$ chelator TPEN (Paoletti et al., 1997). TPEN selectively potentiates NR2A-containing NMDARs due to the removal of $\mathrm{Zn}^{2+}$ inhibition. The actions of TPEN were examined on NMDAR channel openings in outside-out Golgi cell patches from postnatal day (P) 8-10 wild-type mice. Consistent with our data from the rat (Misra et al., 2000a), we found no significant change in charge transfer $(-93 \pm 57 \mathrm{fC}$ vs $-117 \pm 90$ $\mathrm{fC} ; n=5)$ when patches were exposed to $1 \mu \mathrm{M}$ TPEN.

\section{NMDAR-mediated mEPSCs are unchanged by deletion of NR2D}

Excitatory transmission at the parallel fiber input to Golgi cells involves activation of both NMDARs and non-NMDARs (Dieudonné 1998; Misra et al., 2000a). We have shown previously that the NMDAR EPSC at these synapses is reduced (but not fully blocked) by ifenprodil, as expected if it is mediated mainly by NR2B-containing receptors (Misra et al., 2000a). Under these conditions, the residual NMDAR EPSC displays rapid decay kinetics. This appears to be inconsistent with the idea that the current is carried by synaptic receptors composed of diheteromeric NR1/NR2D assemblies, because these are known to deactivate slowly when expressed in recombinant systems (Monyer et al., 1994; Vicini et al., 1998; Wyllie et al., 1998) and in cerebellar cells (Misra et al., 2000b). However, it is not known whether the 
A
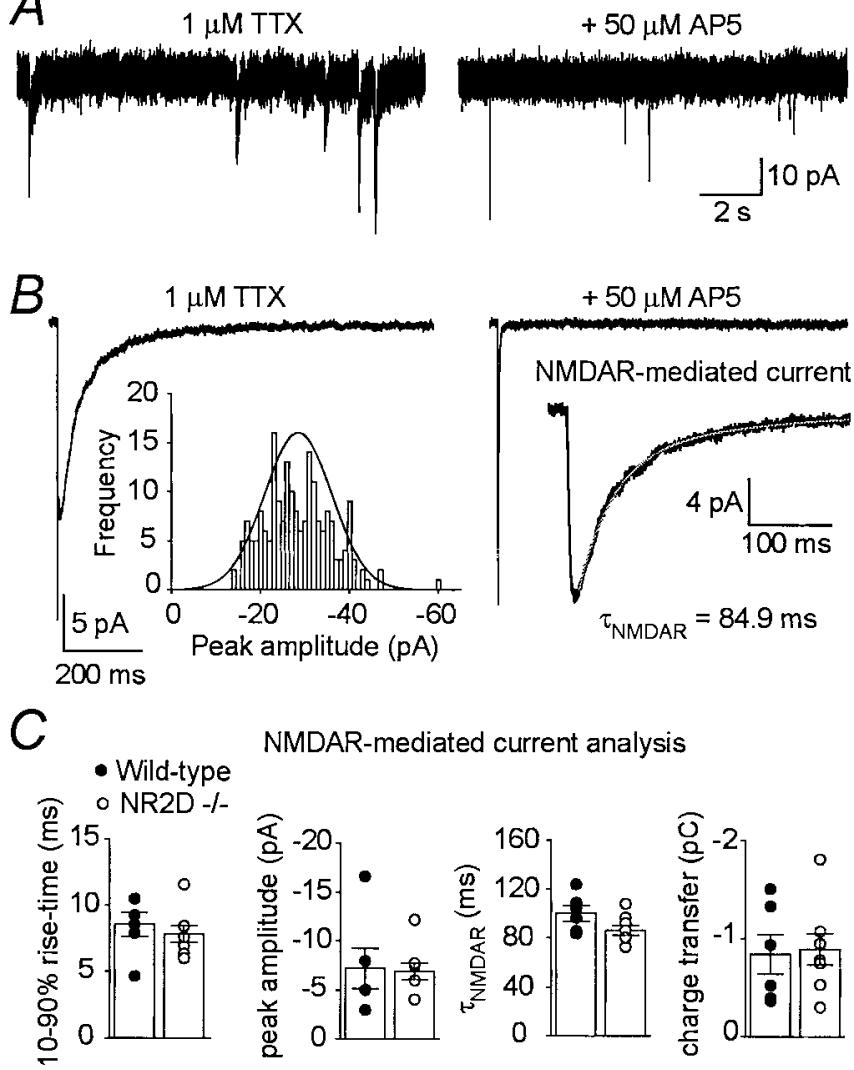

NMDAR-mediated current analysis
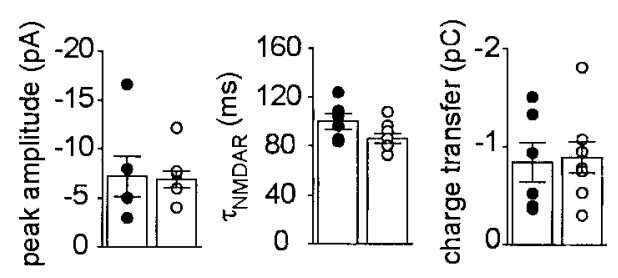

Figure 4. Properties of NMDAR mEPSCs in wild-type and NR2D $-/-$ mice. $A$, Whole-cell records from a P8 Golgi cell $(-30 \mathrm{mV}$ ) in the presence of $1 \mu \mathrm{M}$ TTX (left-hand panel) and $1 \mu \mathrm{M}$ TTX with AP5 (right-hand panel) to yield pure non-NMDAR-mediated mEPSCS. B, Averaged mEPSCs in TTX (left) displaying two components; the inset histogram (left) shows the peak amplitude distribution for mEPSCs recorded in this cell. Averaged mEPSCs in TTX plus AP5 (right) displayed a single component with fast rise and decay. Right-hand inset shows the NMDARmediated component obtained by subtraction ( $\tau=84.9 \mathrm{msec}$, in this example). C, Comparison of NMDAR mEPSCs in wild-type (filled symbols) and NR2D - / - (open symbols) mice showing the lack of significant difference in rise-time, peak amplitude, $\tau$, and charge transfer.

NR2D subunit contributes to the formation of functional triheteromeric receptor assemblies at this or any other synapse.

We therefore next compared synaptic currents in Golgi cells from wild-type and NR2D - / - mice. As shown in Figure 4A, we first examined the properties of individual mEPSCs that were clearly discernible in $1 \mu \mathrm{M}$ TTX. Amplitude distributions of the non-NMDAR mEPSCs, recorded in the presence of the NMDAR antagonist AP5, showed an approximately Gaussian distribution. In neither mouse strain was there a clear dependence of mEPSC amplitude on rise time. Furthermore, there was no significant difference in the mean mEPSC amplitude recorded in wild-type $(-29.0 \pm 2.9 \mathrm{pA} ; n=6)$ versus NR2D $-/-(-31.9 \pm 2.6 \mathrm{pA} ; n=$ 8) mice.

The time course of the synaptic NMDAR-mediated component was examined by constructing average mEPSC waveforms, recorded in the absence and presence of AP5 (Fig. $4 B$ ). Subtraction of the non-NMDAR component (in $50 \mu \mathrm{M}$ AP5) from the dual-component event revealed the waveform of the NMDARmediated mEPSC (Fig. 4B, inset). We could detect no difference in the decay kinetics of these events in wild-type versus NR2D $-/-$ animals. Furthermore, the $10-90 \%$ rise time, peak amplitude, and charge transfer (Fig. 4C) of the NMDAR component (wild type: $0.8 \pm 0.2 \mathrm{pC}, n=6$; NR2D $-/-: 0.9 \pm 0.2 \mathrm{pC}, n=8$ ) were unaffected by the absence of the NR2D subunit. Given the

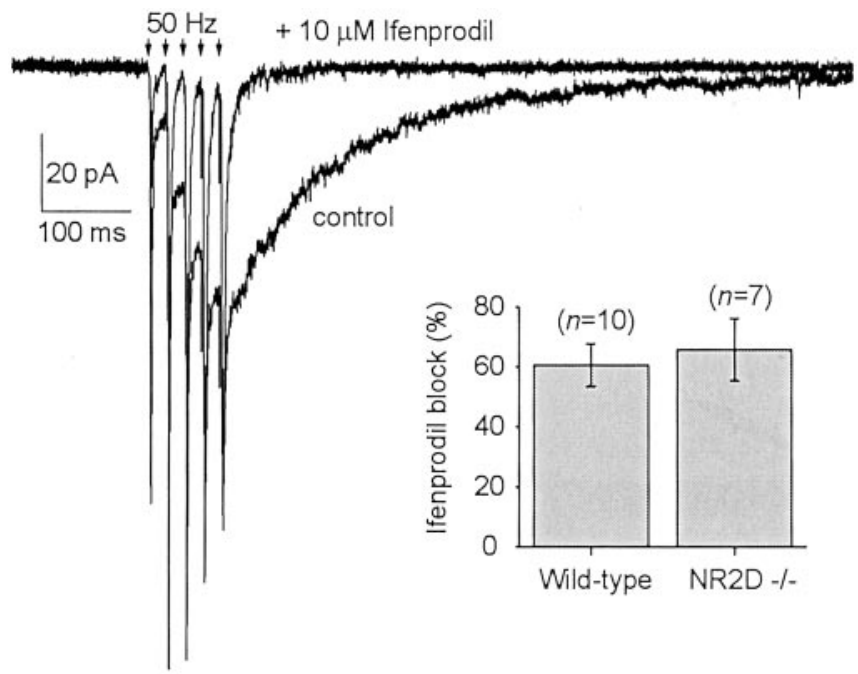

Figure 5. Ifenprodil sensitivity of the NMDAR component of EPSCs in wild-type and NR2D $-/-$ mice. A, Averaged EPSCs from a Golgi cell (P8, wild-type mouse) in response to a $50 \mathrm{~Hz}$ train of stimuli applied to the parallel fiber input. The NMDAR-mediated component was greatly reduced by $10 \mu \mathrm{m}$ ifenprodil. The histogram compares the percentage block in wild-type and NR2D $-1-$ mice. This was measured from charge transfer analysis and calculated relative to the maximum block achieved with $50 \mu \mathrm{M}$ AP5.

clear change in extrasynaptic NMDAR channel kinetics that accompanied loss of the NR2D subunit, the lack of effect on mEPSCs strongly suggests that the NR2D subunit does not contribute to synaptic NMDAR assemblies in these cells.

\section{Ifenprodil sensitivity of evoked NMDAR EPSCs}

We next examined the effect of ifenprodil on parallel fiberevoked NMDAR EPSCs in Golgi cells from NR2D - /- animals. The degree of ifenprodil block was similar in wild-type and NR2D $-/-$ mice. Ifenprodil $(10 \mu \mathrm{M})$ reduced the NMDAR charge transfer by $54.0 \pm 11.2 \%(n=7)$ in cells from wild-type animals and by $51.8 \pm 8.5 \%(n=8)$ in NR2D $-/-$. A similar result was obtained when we examined the ifenprodil sensitivity of spontaneous NMDAR EPSCs (data not shown). Furthermore, the $10-90 \%$ rise time, peak amplitude, and decay of these NMDAR EPSCs were not significantly different between strains, in keeping with our results from mEPSCs.

We therefore next considered whether NR2D-containing NMDARs could be activated during high-frequency trains of synaptic activity. Under these conditions, pooling of transmitter is expected to result in spillover of glutamate and activation of a population of NMDARs not activated by single stimuli. To test this, we stimulated parallel fiber inputs with trains of five stimuli applied at $50 \mathrm{~Hz}$ (Fig. 5). The peak conductance of the evoked non-NMDAR EPSC was more than twice that seen during the $\operatorname{mEPSC}(2176.1 \pm 611.0 \mathrm{pS}, n=10 \mathrm{vs} 967.7 \pm 97.5 \mathrm{pS}, n=6$ for mEPSCs) consistent with release at multiple sites. The peak response of the non-NMDA component to a $50 \mathrm{~Hz}$ train was similar in wild type and NR2D $-/-$ animals (data not shown). The charge transfer occurring during the NMDAR EPSC was greatly enhanced by high-frequency stimulation (from $\sim 0.5$ to $17.9 \pm$ $3.5 \mathrm{pC}, n=10$, in wild-type). Given the size of charge transfer during a typical NMDAR mEPSC $(0.8 \mathrm{pC})$, the increase during a train of stimuli would suggest that a large proportion of the charge is carried by NMDAR channels not normally activated during the mEPSC. Consistent with this conclusion, the decay of the evoked NMDAR component was much slower than that ob- 
served after uniquantal release $\left(\tau_{\mathrm{NMDAR}}=332.5 \pm 49.1 \mathrm{msec}\right.$, $n=10$, compared with $\sim 100$ msec for mEPSCs).

Under these conditions, however, the NMDAR EPSC component in NR2D $-/-$ animals $(13.3 \pm 1.9 \mathrm{pC} ; n=7)$ was not significantly different from that in wild-type mice $(17.9 \pm 3.5$ $\mathrm{pC})$. As illustrated in Figure 5, ifenprodil significantly reduced the total charge transfer by $60.6 \pm 7.2 \%(n=9)$ in wild-type Golgi cells, relative to the total block produced by $50 \mu \mathrm{M}$ AP 5 . A comparable block was obtained in NR2D $-/-$ mice $(65.8 \pm$ $10.4 \% ; n=7)$. Assuming that during these high-frequency trains part of the NMDAR EPSC arises from activation of perisynaptic NMDARs, our observation would suggest that these NMDARs have ifenprodil sensitivity that is similar in wild-type and NR2D $-/-$ mice.

\section{Discussion}

Our experiments provide three main findings. First, they demonstrate that low-conductance NMDAR channels are lost in cells that lack the NR2D subunit. Second, our analysis of the biophysical and pharmacological properties of NMDAR channels in NR2D knock-out mice indicates that NR2D and NR2B coassemble to form a population of functionally distinct receptors. Third, although our experiments suggest the presence of at least two types of NR2D-containing assemblies in the extrasynaptic membrane of Golgi cells, we find no evidence that the NR2D subunit contributes to synaptic receptors, even when coassembled with other NR2 subunits.

\section{Low-conductance NMDAR channels are absent in NR2D ablated mice}

Our previous experiments on rat cerebellar Golgi cells identified high-conductance $(\sim 50 \mathrm{pS})$ NMDAR channels that are sensitive to the NR2B-selective antagonist ifenprodil and lowconductance channels $(20 / 40 \mathrm{pS})$ that exhibit asymmetric gating between conductance states (Misra et al., 2000a), characteristic of NR1/NR2D receptors. The present experiments indicate that mouse Golgi cells express a similar repertoire of NMDAR channels. Moreover, the selective loss of 20/40 pS channels in Golgi cells lacking the NR2D subunit (whereas 50/40 pS openings remain intact) provides direct evidence for the idea that these lowconductance NMDAR channels constitute the native form of NR1/NR2D-subunit containing receptors (Momiyama et al., 1996; Wyllie et al., 1996; Misra et al. 2000b).

\section{NR2D and NR2B subunits coassemble to form a distinct receptor subtype}

Immunoprecipitation and molecular studies suggest that more than one type of NR2 subunit can be contained within NMDAR assemblies (Sheng et al., 1994; Chazot and Stephenson, 1997; Dunah et al., 1998). A growing body of evidence also supports the view that triheteromeric assemblies give rise to discrete receptor subtypes. Thus, cells transfected with NR1, NR2A, and NR2B exhibit reduced ifenprodil sensitivity, compared with diheteromeric NR1/NR2B receptors (Vicini et al., 1998; Tovar and Westbrook 1999). Coexpression of NR2A and NR2D (together with NR1) in Xenopus oocytes also results in single-channel behavior consistent with the presence of triheteromeric assemblies (Cheffings and Colquhoun, 2000). However, despite the widespread distribution of the NR2D subunit in the CNS, it is not known whether triheteromeric NR2D- containing NMDAR assemblies exist in vivo and whether the inclusion of NR2D in such an assembly imparts distinct single-channel properties. These questions are particularly relevant to the developing nervous system, given that NR2D and NR2B are coexpressed in many immature neurons (Akazawa et al., 1994; Monyer et al., 1994; Watanabe et al., 1994). Furthermore, immunohistochemical data suggest that all NR2D-containing receptors in the adult midbrain may be triheteromeric (Dunah et al., 1998).

In the present study, analysis of single-channel currents, recorded from cerebellar Golgi cells in wild-type and NR2D -/mice, demonstrated directly that expression of the NR2D subunit altered both the kinetics and ifenprodil sensitivity of highconductance NMDAR channels. This result suggests the existence of a triheteromeric assembly containing NR1/NR2B/NR2D subunits, implying that at least three types of NMDAR are present in cerebellar Golgi cells at this stage of development. Although NR1/NR2D- and NR1/NR2B-containing receptors give rise to low- (20/40 pS) and high-conductance events (50 pS), respectively, the triheteromeric assembly (NR1/NR2B/NR2D) generates $50 \mathrm{pS}$ channels but with distinct kinetic behavior and pharmacological properties.

Low-conductance NMDARs in the Golgi cell soma behave like recombinant NR1/NR2D receptors (Wyllie et al., 1998) and are also similar to the pure population of native NR1/NR2D channels found in neonatal Purkinje cells (Momiyama et al., 1996; Misra et al., 2000b). The low open probability and low single-channel conductance of this NR1/NR2D channel population means that this NMDAR population will contribute little to the macroscopic currents recorded in Golgi cells. However, it would appear that the triheteromeric NR1/NR2B/NR2D subunit-containing channel population does make a considerable contribution to the population of functional NMDARs recorded in these cells. Indeed, on the basis of the relative proportion of the $\mathrm{IC}_{50(\mathrm{H})}$ and $\mathrm{IC}_{50(\mathrm{~L})}$ components, the ifenprodil inhibition data suggest that more than one-quarter of the functional NMDARs activated in the somatic membrane will be of the triheteromeric type. This is in agreement with the idea that the majority of NR2D-containing NMDARs may be triheteromeric (Dunah et al., 1998).

The expression of a functionally distinct triheteromeric receptor subtype clearly increases the potential for receptor diversity. In this context it is of interest that earlier studies have shown that some recombinant triheteromeric receptors display properties intermediate between the NR2 subunits expressed. For example, NR1/NR2A/NR2B receptors exhibit a slow deactivation time and decreased haloperidol sensitivity (Vicini et al., 1998). Furthermore, NR1/NR2A/NR2D receptors display extended total activation times, but with reduced channel open probability, when compared with NR1/NR2A receptors (Cheffings and Colquhoun, 2000). Our observations suggest that a similar phenomenon occurs with NR1/NR2B/NR2D receptors, because the presence of NR2D resulted in a significant decrease in open peri$\mathrm{od}_{(\mathrm{HIGH})}$ (Figs. 1, 2). Unlike the recombinant NR1/NR2A/NR2D receptors (Cheffings and Colquhoun, 2000), however, we detected no additional conductance states for the native NR1/ NR2B/NR2D assembly. It will be of interest to see whether a native NR1/NR2A/NR2D receptor exhibits additional conductance states.

It is notable that in almost all neurons in which NR2D (or NR2C) is expressed together with other NR2 subunits, only two types of single-channel openings have been reported (Farrant et al., 1994; Momiyama et al., 1996; Takahashi et al., 1996; Plant et al., 1997; Misra et al., 2000a; Momiyama, 2000) (although see Ebralidze et al., 1996). The high-conductance ( $\sim 50 \mathrm{pS})$ events are believed to arise from native NR2A- and NR2B-containing receptors, whereas low-conductance (38-18 pS) events arise 
from NR2C- and NR2D-containing receptors. Our experiments suggest that the absence of other conductance levels does not indicate a lack of triheteromeric receptors because NR1/NR2B/ NR2D and NR1/NR2B assemblies exhibit similar single-channel conductances.

Not all low-conductance events necessarily arise from NR1/ NR2D- or NR1/NR2C-containing NMDARs. For example, there is compelling evidence that the NR3A subunit can coassemble with NR1/NR2 receptors to produce a functionally distinct recombinant NR1/NR2A/NR3A receptor with low-conductance channel openings (Perez-Otano et al., 2001). Therefore, it is only in the absence of NR3 (as in the cerebellum) that lowconductance NMDAR openings provide an unambiguous singlechannel signature for NR2C- or NR2D-containing diheteromeric receptors. In this respect it is clear that other native NMDAR channel conductance levels have been described, with subunit compositions that remain to be identified (Palecek et al., 1999). Also, in a recent study of NMDAR channels in neonatal rat hippocampal neurons thought to express NR2D, it has been suggested that a single type of triheteromeric receptor may switch between two states, giving rise both to high- and lowconductance modes. It is therefore conceivable that a proportion of the low-conductance events observed in Golgi cells may reflect modal gating of the triheteromeric NR2D-containing receptor (Pina-Crespo and Gibb, 2002).

\section{NR2D-containing NMDARs are absent from Golgi cell synapses}

Previous studies on native NMDARs in cultured neurons and brain slices have provided evidence for synaptic triheteromeric assemblies composed of NR1/NR2A/NR2B (Tovar and Westbrook, 1999) and NR1/NR2A/NR2C (Cathala et al., 2000). For example, it has been suggested that extrasynaptic NMDARs in cultured hippocampal cells are composed of NR1/NR2B assemblies, whereas the NMDAR EPSCs in these cells appear to be mediated by two populations of receptors, most of which show a reduced sensitivity to ifenprodil consistent with the presence of a triheteromeric NR1/NR2A/NR2B assembly (Kew et al., 1998; Tovar and Westbrook, 1999).

There is currently no evidence to suggest that the NR2D subunit is incorporated into synaptic NMDARs. Our previous experiments have shown that, like their recombinant counterparts (Monyer et al., 1994; Vicini et al., 1998; Wyllie et al., 1998), native NR1/NR2D receptors display unusually slow deactivation kinetics $(\tau \sim 3-4 \mathrm{sec})$ (Misra et al., 2000b). This would allow their presence to be readily identified at synapses. In the developing cerebellum, several cell types express functional NR2Dcontaining extrasynaptic NMDARs, as is evident from singlechannel data (Momiyama et al., 1996; Cull-Candy et al., 1998; Clark and Cull-Candy, 1999; Misra et al., 2000a). Despite this, there is as yet little evidence for the presence of NR1/NR2D diheteromeric receptors in the postsynaptic membrane of these neurons (Misra et al., 2000a,b; Momiyama, 2000; Clark and CullCandy, 2002). Previous observations could not exclude the possibility that triheteromeric NR2D-containing assemblies are present at certain synapses. However, the lack of change in the kinetics and ifenprodil sensitivity of the NMDAR EPSCs that we observed in NR2D knock-out mice strongly suggests that both diheteromeric and triheteromeric NR2D subunit-containing assemblies are absent from Golgi cell synapses. Furthermore, although we observed a greatly increased NMDAR-mediated response during high-frequency synaptic activity at parallel fiber inputs, we found no evidence that NR2D-containing receptors could contribute to this current.

Because triheteromeric NR2D-containing receptors can be detected in the extrasynaptic membrane of Golgi cells, they are clearly assembled and delivered to the cell surface where they might have been expected to move laterally into synaptic sites, as described for other NMDA receptor subtypes (Tovar and Westbrook, 2002). There is growing evidence that the synaptic localization of NMDARs is determined by interaction of NMDAR subunits with intracellular proteins that anchor or stabilize the receptor in the postsynaptic density (Sheng and Pak, 2000) and that the identity of the NR2 subunit influences these processes (Quinlan et al., 1999; Tovar and Westbrook 1999; Barria and Malinow, 2002; Prybylowski et al., 2002). In this context, it is of interest that the C-terminal tail of the NR2D (and NR2C) subunit differs from that of NR2A and NR2B, in terms of the motif that mediates its binding to PSD-95 (postsynaptic density-95). However, in contrast to the NR2D-containing receptors, both diheteromeric and triheteromeric NR2C-containing receptors appear to be activated during synaptic transmission in those cells in which it is expressed (Takahashi et al., 1996; Cathala et al., 2000). Our finding that NR2D subunits do not contribute to the synaptic receptors in Golgi cells, even when coassembled with other NR2 subunits, raises the obvious question of whether incorporation of NR2D causes loss of targeting to the postsynaptic membrane. It remains to be seen whether, under particular circumstances, the NR2D subunit is delivered to synapses or whether it serves a purely extrasynaptic role in central neurons.

\section{References}

Akazawa C, Shigemoto R, Bessho Y, Nakanishi S, Mizuno N (1994) Differential expression of five $N$-methyl-D-aspartate receptor subunit mRNAs in the cerebellum of developing and adult rats. J Comp Neurol 347:150-160.

Barria A, Malinow R (2002) Subunit-specific NMDA receptor trafficking to synapses. Neuron 35:345-353.

Béhé P, Stern P, Wyllie DJ, Nassar M, Schoepfer R, Colquhoun D (1995) Determination of NMDA NR1 subunit copy number in recombinant NMDA receptors. Proc R Soc Lond B Biol Sci 262:205-213.

Cathala L, Misra C, Cull-Candy S (2000) Developmental profile of the changing properties of NMDA receptors at cerebellar mossy fiber-granule cell synapses. J Neurosci 20:5899-5905.

Chazot PL, Stephenson FA (1997) Molecular dissection of native mammalian forebrain NMDA receptors containing the NR1 C2 exon: direct demonstration of NMDA receptors comprising NR1, NR2A, and NR2B subunits within the same complex. J Neurochem 69:2138-2144.

Cheffings CM, Colquhoun D (2000) Single channel analysis of a novel NMDA channel from Xenopus oocytes expressing recombinant NRla, NR2A and NR2D subunits. J Physiol (Lond) 526:481-491.

Clark BA, Cull-Candy SG (1999) What is the role of NMDA receptors in cerebellar molecular interneurons? Soc Neurosci Abstr 25:993.

Clark BA, Cull-Candy SG (2002) Activity-dependent recruitment of extrasynaptic NMDA receptor activation at an AMPA receptor-only synapse. J Neurosci 22:4428-4436.

Colquhoun D, Sigworth FW (1995) Fitting and statistical analysis of single channel records. In: Single-channel recording, Ed 2 (Neher E, Sakmann B, eds), pp 483-587. New York: Plenum.

Cull-Candy SG, Brickley SG, Misra C, Feldmeyer D, Momiyama A, Farrant M (1998) NMDA receptor diversity in the cerebellum: identification of subunits contributing to functional receptors. Neuropharmacology 37:1369-1380.

Cull-Candy S, Brickley S, Farrant M (2001) NMDA receptor subunits: diversity, development and disease. Curr Opin Neurobiol 11:327-335.

Das S, Sasaki YF, Rothe T, Premkumar LS, Takasu M, Crandall JE, Dikkes P, Conner DA, Rayudu PV, Cheung W, Chen HS, Lipton SA, Nakanishi N. (1998) Increased NMDA current and spine density in mice lacking the NMDA receptor subunit NR3A. Nature 393:377-381. 
Dieudonné S (1995) Glycinergic synaptic currents in Golgi cells of the rat cerebellum. Proc Natl Acad Sci USA 92:1441-1445.

Dieudonné S (1998) Submillisecond kinetics and low efficacy of parallel fibre-Golgi cell synaptic currents in the rat cerebellum. J Physiol (Lond) 510:845-866.

Dingledine R, Borges K, Bowie D, Traynelis SF (1999) The glutamate receptor ion channels. Pharmacol Rev 51:7-61.

Dunah AW, Luo J, Wang YH, Yasuda RP, Wolfe BB (1998) Subunit composition of $N$-methyl-D-aspartate receptors in the central nervous system that contain the NR2D subunit. Mol Pharmacol 53:429-437.

Ebralidze AK, Rossi DJ, Tonegawa S, Slater NT (1996) Modification of NMDA receptor channels and synaptic transmission by targeted disruption of the NR2C gene. J Neurosci 16:5014-5025.

Farrant M, Feldmeyer D, Takahashi T, Cull-Candy SG (1994) NMDAreceptor channel diversity in the developing cerebellum. Nature 368:335-339.

Hollmann M (1999) Structure of ionotropic glutamate receptors. In: Ionotropic glutamate receptors in the CNS (Jonas P, Monyer H, eds), pp 1-98. Berlin: Springer.

Howe JR, Cull-Candy SG, Colquhoun D (1991) Currents through single glutamate receptor channels in outside-out patches from rat cerebellar granule cells. J Physiol (Lond) 432:143-202.

Ikeda K, Araki K, Takayama C, Inoue Y, Yagi T, Aizawa S, Mishina M (1995) Reduced spontaneous activity of mice defective in the epsilon 4 subunit of the NMDA receptor channel. Brain Res Mol Brain Res 33:61-71.

Kew JN, Richards JG, Mutel V, Kemp JA (1998) Developmental changes in NMDA receptor glycine affinity and ifenprodil sensitivity reveal three distinct populations of NMDA receptors in individual rat cortical neurons. J Neurosci 18:1935-1943.

Kutsuwada T, Kashiwabuchi N, Mori H, Sakimura K, Kushiya E, Araki K, Meguro H, Masaki H, Kumanishi T, Arakawa M, Mishina M (1992) Molecular diversity of the NMDA receptor channel. Nature 358:36-41.

Laube B, Kuhse J, Betz H (1998) Evidence for a tetrameric structure of recombinant NMDA receptors. J Neurosci 18:2954-2961.

Misra C, Brickley SG, Farrant M, Cull-Candy SG (2000a) Identification of subunits contributing to synaptic and extrasynaptic NMDA receptors in Golgi cells of the rat cerebellum. J Physiol (Lond) 524:147-162.

Misra C, Brickley SG, Wyllie DJA, Cull-Candy SG (2000b) Slow deactivation kinetics of NMDA receptors containing NR1 and NR2D subunits in rat cerebellar Purkinje cells. J Physiol (Lond) 525:299-305.

Misra C, Brickley SG, Mok MHS, Mishina M, Cull-Candy SG (2003) NMDAR channels in cerebellar Golgi cells of wild-type and NR2D subunit ablated mice. J Physiol (Lond) 547P:45.

Momiyama A (2000) Distinct synaptic and extrasynaptic NMDA receptors identified in dorsal horn neurones of the adult rat spinal cord. J Physiol (Lond) 523:621-628.

Momiyama A, Feldmeyer D, Cull-Candy SG (1996) Identification of a native low-conductance NMDA channel with reduced sensitivity to $\mathrm{Mg}^{2+}$ in rat central neurones. J Physiol (Lond) 494:479-492.

Monyer H, Burnashev N, Laurie DJ, Sakmann B, Seeburg PH (1994) Developmental and regional expression in the rat brain and functional properties of four NMDA receptors. Neuron 12:529-540.

Moriyoshi K, Masu M, Ishii T, Shigemoto R, Mizuno N, Nakanishi S (1991) Molecular cloning and characterization of the rat NMDA receptor. Nature 354:31-37.

Palecek JI, Abdrachmanova G, Vlachova V, Vyklick L Jr (1999) Properties of NMDA receptors in rat spinal cord motoneurons. Eur J Neurosci 11:827-836.

Paoletti P, Ascher P, Neyton J (1997) High-affinity zinc inhibition of NMDA NR1-NR2A receptors. J Neurosci 17:5711-5725.

Perez-Otano I, Schulties CT, Contractor A, Lipton SA, Trimmer JS, Sucher
NJ, Heinemann SF (2001) Assembly with NR1 subunit is required for surface expression of NR3A-containing NMDA receptors. J Neurosci 21:175-218.

Perin-Dureau F, Rachline J, Neyton J, Paoletti P (2002) Mapping the binding site of the neuroprotectant ifenprodil on NMDA receptors. J Neurosci 22:5955-5965.

Pina-Crespo JC, Gibb AJ (2002) Subtypes of NMDA receptors in new-born rat hippocampal granule cells. J Physiol (Lond) 541:41-64.

Plant T, Schirra C, Garaschuk O, Rossier J, Konnerth A (1997) Molecular determinants of NMDA receptor function in GABAergic neurones of rat forebrain. J Physiol (Lond) 499:47-63.

Premkumar LS, Auerbach A (1997) Stoichiometry of recombinant $\mathrm{N}$-methyl-D-aspartate receptor channels inferred from single-channel current patterns. J Gen Physiol 110:485-502.

Prybylowski K, Fu Z, Losi G, Hawkins LM, Luo J, Chang K, Wenthold RJ, Vicini S (2002) Relationship between availability of NMDA receptor subunits and their expression at the synapse. J Neurosci 22:8902-8910.

Quinlan EM, Philpot BD, Huganir RL, Bear MF (1999) Rapid, experiencedependent expression of synaptic NMDA receptors in visual cortex in vivo. Nat Neurosci 2:352-357.

Sheng M, Pak DTS (2000) Ligand-gated ion channel interactions with cytoskeletal and signaling proteins. Annu Rev Physiol 62:755-778.

Sheng M, Cummings J, Roldan LA, Jan YN, Jan LY (1994) Changing subunit composition of heteromeric NMDA receptors during development of rat cortex. Nature 368:144-147.

Sugihara H, Moriyoshi K, Ishii T, Masu M, Nakanishi S (1992) Structures and properties of seven isoforms of the NMDA receptor generated by alternative splicing. Biochem Biophys Res Commun 185:826-832.

Takahashi T, Feldmeyer D, Suzuki N, Onodera K, Cull-Candy SG, Sakimura K, Mishina M (1996) Functional correlation of NMDA receptor $\in$ subunits expression with the properties of single-channel and synaptic currents in the developing cerebellum. J Neurosci 16:4376-4382.

Takeuchi T, Kiyama Y, Nakamura K, Tsujita M, Matsuda I, Mori H, Munemoto Y, Kuriyama H, Natsume R, Sakimura K, Mishina M (2001) Roles of the glutamate receptor epsilon2 and delta2 subunits in the potentiation and prepulse inhibition of the acoustic startle reflex. Eur J Neurosci 14:153-160.

Thompson CL, Drewery DL, Atkins HD, Stephenson FA, Chazot PL (2002) Immunohistochemical localization of $N$-methyl-D-aspartate receptor subunits in the adult murine hippocampal formation: evidence for a unique role of the NR2D subunit. Brain Res Mol Brain Res 102:55-61.

Tovar KR, Westbrook GL (1999) The incorporation of NMDA receptors with a distinct subunit composition at nascent hippocampal synapses in vitro. J Neurosci 19:4180-4188.

Tovar KR, Westbrook GL (2002) Mobile NMDA receptors at hippocampal synapses. Neuron 34:255-264.

Vicini S, Wang JF, Li JH, Zhu WJ, Wang YH, Luo JH, Wolfe BB, Grayson DR (1998) Functional and pharmacological differences between recombinant $N$-methyl-D-aspartate receptors. J Neurophysiol 79:555-566.

Watanabe M, Mishina M, Inoue Y (1994) Distinct spatiotemporal expressions of five NMDA receptor channel subunit mRNAs in the cerebellum. J Comp Neurol 343:513-519.

Williams K (1993) Ifenprodil discriminates subtypes of the NMDA receptor: selectivity and mechanisms at recombinant heteromeric receptors. Mol Pharmacol 44:851-859.

Wyllie DJ, Béhé P, Colquhoun D (1998) Single-channel activations and concentration jumps: comparison of recombinant NR1a/NR2A and NR1a/NR2D NMDA receptors. J Physiol (Lond) 510:1-18.

Wyllie DJA, Béhé P, Nassar M, Schoepfer R, Colquhoun D (1996) Singlechannel currents from recombinant NMDA NR1a/NR2D receptors expressed in Xenopus oocytes. Proc R Soc Lond B Biol Sci 263:1079-1086. 